\title{
Effect of Elevated Temperature on Performance of Concrete Containing Supplementary Cementitious Material Derived from Coir Industry
}

\author{
Balagopal $\mathbf{V}^{1}$, Viswanathan T.S $\mathrm{S}^{2}$ \\ ${ }^{1}$ Research Scholar, Department of Structural and Geotechnical Engineering, School of Civil Engineering, Vellore Institute of \\ Technology, Vellore, India, 632014 \\ ${ }^{2}$ Associate Professor, Department of Structural and Geotechnical Engineering, School of Civil Engineering, Vellore Institute of \\ Technology, Vellore, India, 632014 \\ Corresponding author : viswanathan.ts@ vit.ac.in
}

\begin{abstract}
Elevated temperature studies on concrete have gained importance since the exposure of concrete members to higher temperatures affects the overall structural stability. This paper explains the behaviour and performance of concrete containing a supplementary cementitious material derived from coir industry, Coir Pith Ash (CPA), when subjected to elevated temperature environments. Concrete specimens with CPA content varying from $0 \%$ to $20 \%$ were taken into consideration and the specimens were exposed to elevated temperature levels. The heating of specimens was conducted in an electric furnace. The parameters considered for the study includeresidual compressive strength, visual observation, and ultrasonic pulse velocity.Effect of aircooling and water-cooling regimes were also studied.The test results proved the superior performance of CPA concrete over normal control mix concrete. Among the cooling regimes, the air-cooling method was found to be better than water cooling method.
\end{abstract}

Key words: Concrete, Cement,Elevated temperature, Coir Pith, Coir Pith Ash

\section{INTRODUCTION}

Replacing cement with other sustainable constituents protects the environment as well as the economy. Cement is one of the most popular binding materialsused in concrete and its usage across the world is more than 4.1 million [1]. Several industrial and agricultural by-products have been used as supplementary cementitious materials (SCMs) in concrete and they improve the overall performance of concrete.Coir is abundantly available in many countries and coir pith is the byproduct obtained during the processing of coir which is spongy in nature. Among the various states of India, Kerala, Tamilnadu,Andra Pradesh and Karnataka produces $89 \%$ of all the coconuts produced in the country [2]. Presence of lignin makes the disintegration of coir pith very [3].Also, coir pith can be converted into an efficient fuel due to its high calorific value of $3975 \mathrm{kcal}$ per $\mathrm{kg}$ [4].The overall load-carrying capacity gets reduced when the members are exposed to elevated temperature. Elevated temperature situations can arise during circumstances like reactor vessels, fire accidents and nuclear power stations. Under those circumstances, the members will have to carry load under very high temperatures conditions that can go beyond $1350{ }^{\circ} \mathrm{C}$. When a concrete member is subjected to conditions of extreme temperatures, the surface of the member gets exposed first. Due to low conductivity, there occurs a temperature gradient between internal and external portions of the members which in turn induces additional stresses inside the member. Physical and chemical characteristics of concrete also get affected by elevated temperatures. The predominant changes initiate beyond 110 ${ }^{\circ} \mathrm{C}$ when there occurs expulsion of chemically bounded water present in the concrete matrix. When the temperature goes beyond $300{ }^{\circ} \mathrm{C}$, micro-cracks starts to develop and propagate through the concrete mass and the main reason responsible for this include intense dehydration and formation of internal stress due to expansion of aggregates [5]. Dissociation of calcium hydroxide, which is a by-product of cement hydration takes place when the temperature rises above 530 ${ }^{\circ} \mathrm{C}$. causing extensive shrinkage [6,7]. Various physical characteristicsalso get altered by elevated temperatures. Thus, the overall desirable concrete characteristics are highly affected by elevated temperatures and improvement of the performance of concrete under elevated temperatures is very significant $[8,9]$

\section{MATERIALS AND METHODS}

\subsection{Materials}

The materials used in the research include cement, aggregates, water and CPA. For the study, OPC confirming to IS 12269: 2013 and the manufactured by ultra tech cement was considered [10].The specific gravity of the cement was 3.15 . The fineness of cement used was $8 \%$. The value of normal consistency was in the range of $36.75 \%$. The initial and final setting time values were 77 minutes and 320 minutes respectively. 
Saturated surface dried locally available river sand with fineness modulus of 3.53 and a specific gravity of 2.67 were used as fine aggregates.Coarse aggregates passing through 20 $\mathrm{mm}$ and retained on $10 \mathrm{~mm}$ sieves, with specific gravity 2.70 and fineness modulus of 7.22 were used. The water absorption value of fine aggregate was $1.39 \%$ andthat of coarseaggregatewas $0.81 \%$.For preparing Coir pith ash, the raw coir pith was initially allowed to undergo drying for 24 hours. The coir pith was then heated for 4 hours and at a temperature of $400^{\circ} \mathrm{C}$. The obtained ash was stored in airtight closed containers after sieving through 90-micron sieve.

\subsection{Concrete Mix Proportion \& Manufacture}

The mix design calculations were carried out as per IS method and the code followed was IS 10262:2009[11] The obtained mix proportion was 1:1.5:2.58 and a water-cement ratio adopted was 0.45 .

The mix proportion details used for the study are shown below

- $\mathrm{CM}$ - Control Mix

- $\quad \mathrm{CC} 05$ - $5 \%$ CPA and 95\% Cement

- $\quad \mathrm{CC} 10-10 \%$ CPA and 90\% Cement

- CC15-15\% CPA and 85\% Cement

- $\quad$ CC20 - 20\% CPA and 80\% Cement

\subsection{Heating Procedure}

The concrete cube specimens of $100 \mathrm{~mm}$ size were subjected to various elevated temperature levels of $27^{\circ} \mathrm{C}, 200^{\circ} \mathrm{C}, 400$ ${ }^{\circ} \mathrm{C}, 600{ }^{\circ} \mathrm{C}$ and $800{ }^{\circ} \mathrm{C}$. To attain the elevated temperatures, an electric furnace was used. Once the specimens reach the peak temperatures, the attained maximum temperature was sustained for 1 hour. Two methods of cooling were studied, air cooling and water cooling. Separate specimens were cast for the two cooling regimes. In air cooling, the specimens were brought back to room temperature slowly in by the action of air. In the case of water curing, sudden cooling occurred by spraying water to the specimens causing thermoshock conditions

\subsection{Compressive Strength of Specimens}

The variation in compressive strength of CPA blended concrete specimens was studied by exposing the specimens to various temperatures and testing the specimens after coming back to room temperature. A compression testing machine having a maximum capacity of $2000 \mathrm{kN}$ was used to carry out the test and the test was carried out as per IS 516: 1959.The specimens used were cubes of $100 \mathrm{~mm}$ size [12].

To assess the performance of CPA concrete, residual compressive strength (RCS) was calculated using the following formula

$\operatorname{RCS}(\%)=(\mathrm{x} / \mathrm{y}) \mathrm{X} 100$
Where,

' $\mathrm{x}$ ' is the compressive strength of CPA blended concrete specimens subjected to elevated temperatures expressed in $\mathrm{MPa}$

and

' $y$ ' is the compressive strengthof CPA blendedconcrete specimens at $27^{\circ} \mathrm{C}$ expressed in MPa

RCS provides an idea about the extent up to which a specimen retains its strength after suffering higher temperatures environments.

\subsection{Variation in Ultrasonic Pulse Velocity}

When a concrete member or specimen is subjected to higher temperature levels, the internal and external structure undergo several alterations. These variations were checked by conducting ultra-sonic pulse velocity (UPV) tests as per IS 13311 (Part 1): 1992 [13]. The specimens were exposed to higher temperatures and UPV test was carried out on these specimens. Then the obtained values were compared with standard values given in IS 13311 (Part 1): 1992 to assess the concrete quality. As per IS 13311 (Part 1): 1992, if the UPV is more than $4.5 \mathrm{Km} / \mathrm{s}$, the quality of concrete is considered to be 'Excellent'. When the UPV is between 3.5- $4.5 \mathrm{Km} / \mathrm{S}$, the quality will be 'Good'. When the UPV of the specimen ranges between $3.5-4.5 \mathrm{Km} / \mathrm{s}$, it shows 'moderate' quality and finally, when the UPV goes below $3.0 \mathrm{Km} / \mathrm{s}$, the quality of the specimen seems 'doubtful'.In the study, effects and comparison of two different cooling methods were considered ie, air cooling and water cooling.

\subsection{Analysis of Specimens Exposed to Elevated Temperature by Visual Observation}

Even though this cannot be considered as an accurate and quantitative method to understand the concrete quality, the method could give an idea about the overall physical appearance and integrity of the specimens. Various parameters like surface texture and presence of cracks were studied.

\section{RESULTS}

\subsection{Influence of elevated temperature on RCS}

The results of the compressive strength test on specimens blended with CPA,subjected to higher temperatures followed by air cooling regime is shown in Table 1 . The strength of CC05 was more than $\mathrm{CM}$ at al curing periods. CC10 and $\mathrm{CC} 15$ possessed better compressive strength than $\mathrm{CM}$ at 600 ${ }^{\circ} \mathrm{C}$ and $800{ }^{\circ} \mathrm{C}$. At room temperature and $200^{\circ} \mathrm{C}, \mathrm{CM}, \mathrm{CC} 05$, $\mathrm{C} 10$ and $\mathrm{C} 15$ satisfied the requirements of M25 concrete. At $400{ }^{\circ} \mathrm{C}$ exposure conditions, only $\mathrm{CC} 05$ could meet the requirements of M25. 
Balagopal V et al., International Journal of Emerging Trends in Engineering Research, 8(8), August 2020, 4496 - 4501

Table 1: Variation of compressive strength of CPA blended specimens with elevated temperature subjected to air cooling

\begin{tabular}{|c|c|c|c|c|c|}
\hline \multirow{2}{*}{$\begin{array}{c}\text { Temperature } \\
\left({ }^{\mathbf{0}} \mathbf{C}\right)\end{array}$} & \multicolumn{5}{|c|}{ Compressive Strength } \\
\cline { 2 - 6 } & $\mathbf{C M}$ & $\mathbf{C C 0 5}$ & $\mathbf{C C 1 0}$ & $\mathbf{C C 1 5}$ & $\mathbf{C C 2 0}$ \\
\hline 27 & 33.60 & 36.20 & 31.17 & 27.40 & 20.13 \\
\hline 200 & 29.97 & 33.30 & 28.67 & 25.73 & 19.20 \\
\hline 400 & 22.07 & 25.90 & 23.50 & 21.70 & 16.97 \\
\hline 600 & 18.77 & 22.03 & 21.43 & 19.53 & 14.90 \\
\hline 800 & 10.30 & 13.23 & 12.50 & 13.03 & 10.40 \\
\hline
\end{tabular}

Considering the RCS (\%) of air-cooled specimens with CPA, at a particular temperature, the RCS (\%) increased with increase in the ash content. For a particular mix, there was a reduction in the residual compressive strength with a rise in exposure temperature. Figure 1 shows the RCS (\%) of CPA blended concrete specimens subjected to air cooling

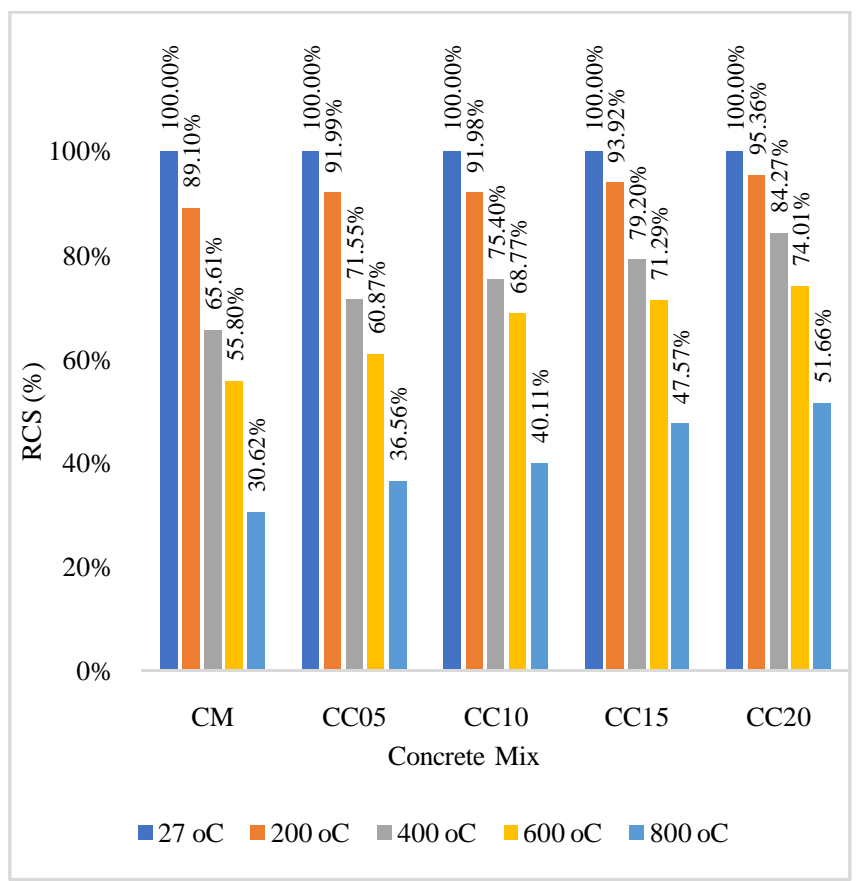

Figure 1:RCS of air-cooled CPA concrete

The compressive strength of specimens containing CPA subjected to water cooling regime is shown in Table 2.Strength of $\mathrm{CC} 05$ was more than $\mathrm{CM}$ at all exposure scenarios. Among the specimens not exposed to elevated temperatures, $\mathrm{CM}, \mathrm{CC} 05, \mathrm{CC} 10$, and $\mathrm{CC} 15$ met the requirements of M25 concrete. After exposing to $200{ }^{\circ} \mathrm{C}$, CM, CC05, and CC10 had strength more than $25 \mathrm{~N} / \mathrm{mm}^{2}$. All specimens after exposing to $400{ }^{\circ} \mathrm{C}$ and higher temperatures could not meet the requirements of M25 concrete. At exposure condition of $800{ }^{\circ} \mathrm{C}$, the strengths of $\mathrm{CC} 05, \mathrm{CC} 10, \mathrm{CC} 15$ and $\mathrm{CC} 20$ were higher than that of $\mathrm{CM}$.
Table 2:Variation of compressive strength of CPA blended specimens with elevated temperature subjected to water cooling

\begin{tabular}{|c|c|c|c|c|c|}
\hline \multirow{2}{*}{$\begin{array}{l}\text { Temperature } \\
\left({ }^{\circ} \mathrm{C}\right)\end{array}$} & \multicolumn{5}{|c|}{ Compressive Strength $\left(\mathrm{N} / \mathrm{mm}^{2}\right)$} \\
\hline & CM & $\mathrm{CCO5}$ & CC10 & CC15 & $\mathrm{CC20}$ \\
\hline 27 & 33.63 & 36.20 & 31.17 & 27.40 & 20.13 \\
\hline 200 & 28.90 & 32.40 & 27.97 & 24.73 & 18.30 \\
\hline 400 & 20.27 & 24.63 & 22.40 & 20.13 & 15.17 \\
\hline 600 & 16.70 & 20.23 & 18.50 & 17.60 & 13.20 \\
\hline 800 & 9.33 & 11.10 & 10.90 & 10.53 & 10.10 \\
\hline
\end{tabular}

Figure 2 shows the RCS (\%) of CPA blended concrete specimens subjected to water cooling. The difference between the maximum and minimum RCS (\%) values decreased as the percentage of ash increased.

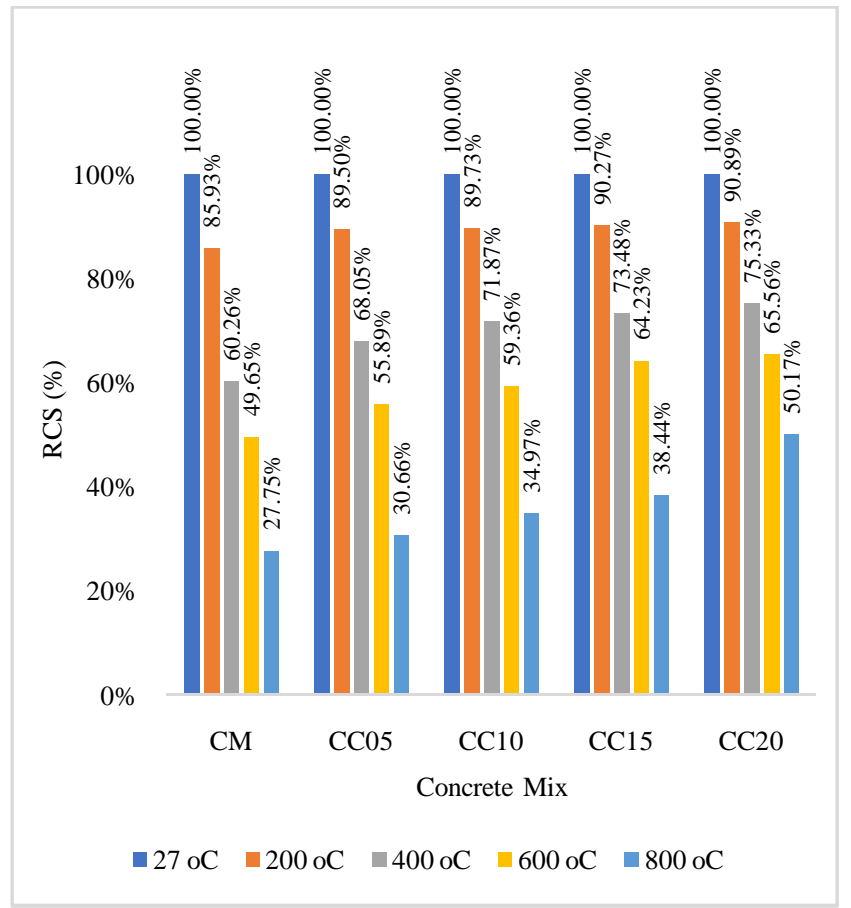

Figure 2: RCS of Water-cooled CPAconcrete

\subsection{Influence of the method of the cooling on RCS}

The RCS is seriously affected by the method of cooling adopted (figure 3 to figure 7).By considering the RCS, it was understood that, when compared to water cooling method, the air cooling methodperformed better. 


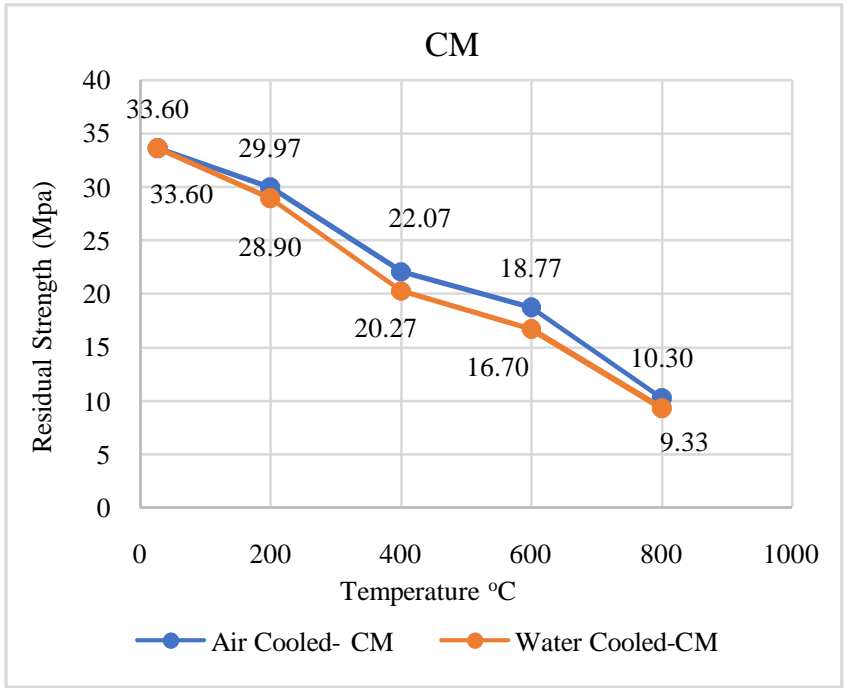

Figure 3: Influence of the method of cooling - CM

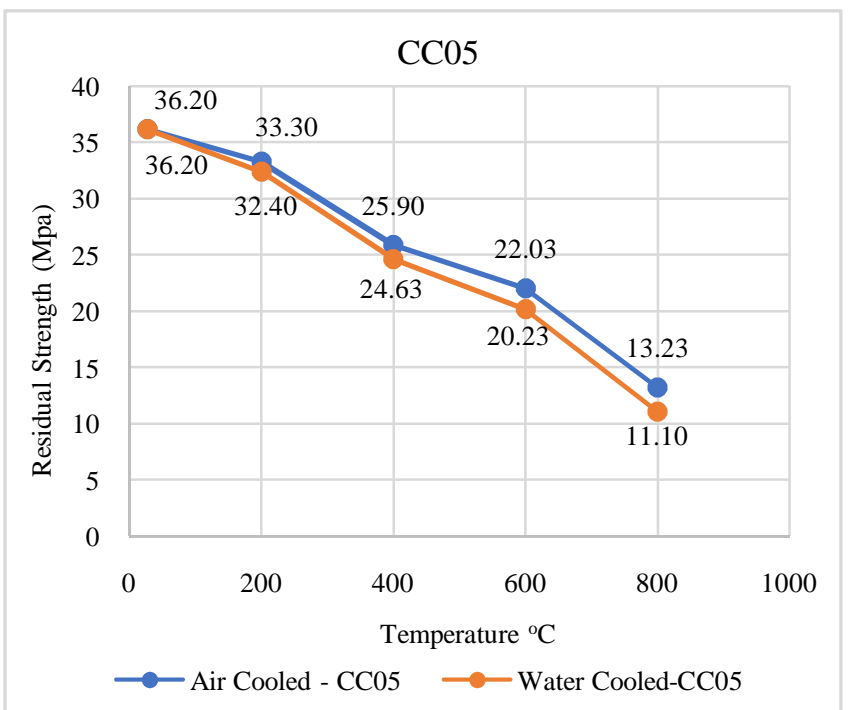

Figure 4:Influence of the method of cooling on RCS-CC05

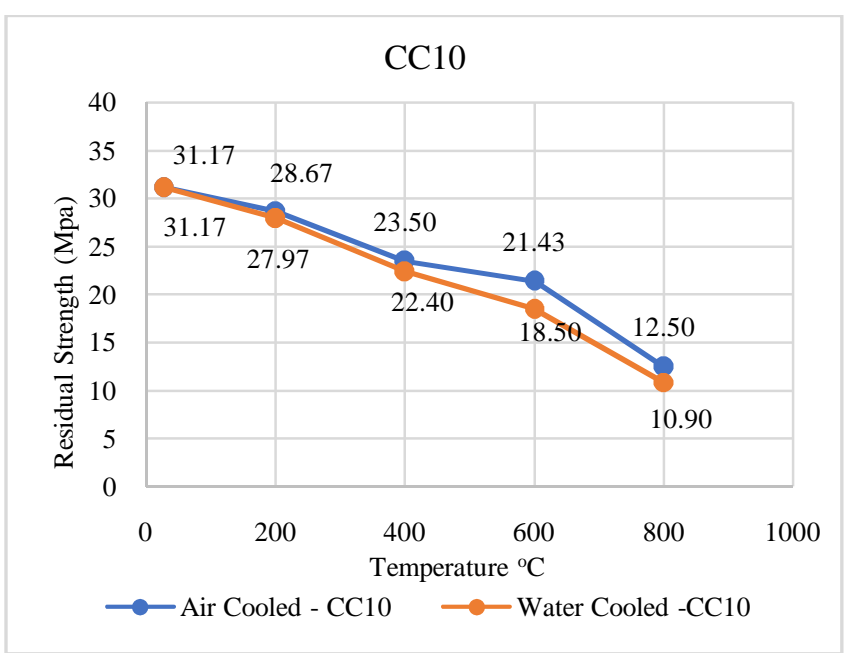

Figure 5:Influence of the method of cooling on RCS-CC10

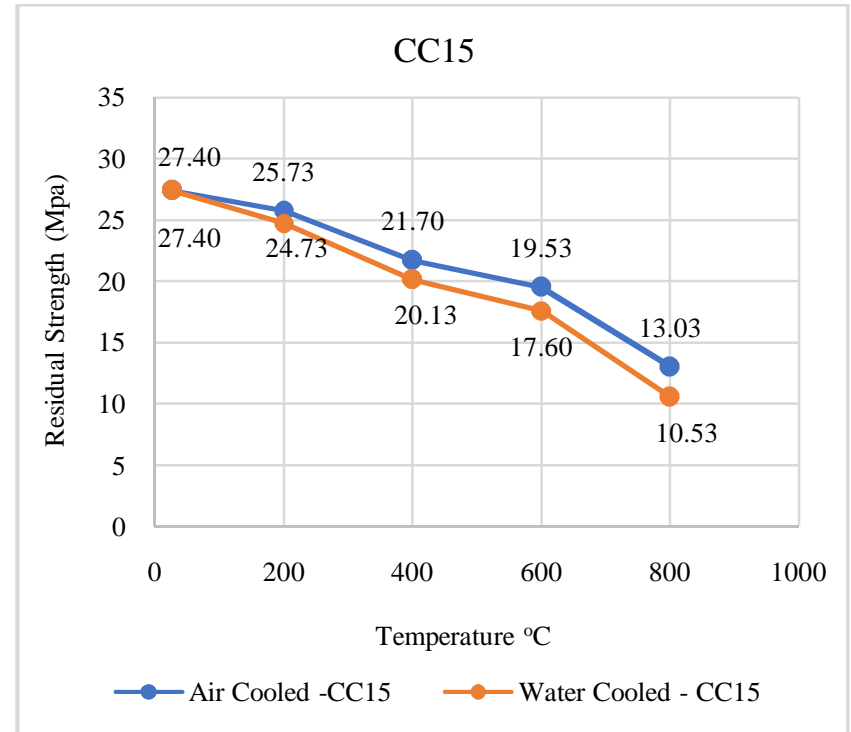

Figure 6:Influence of the method of cooling on RCS- CC15

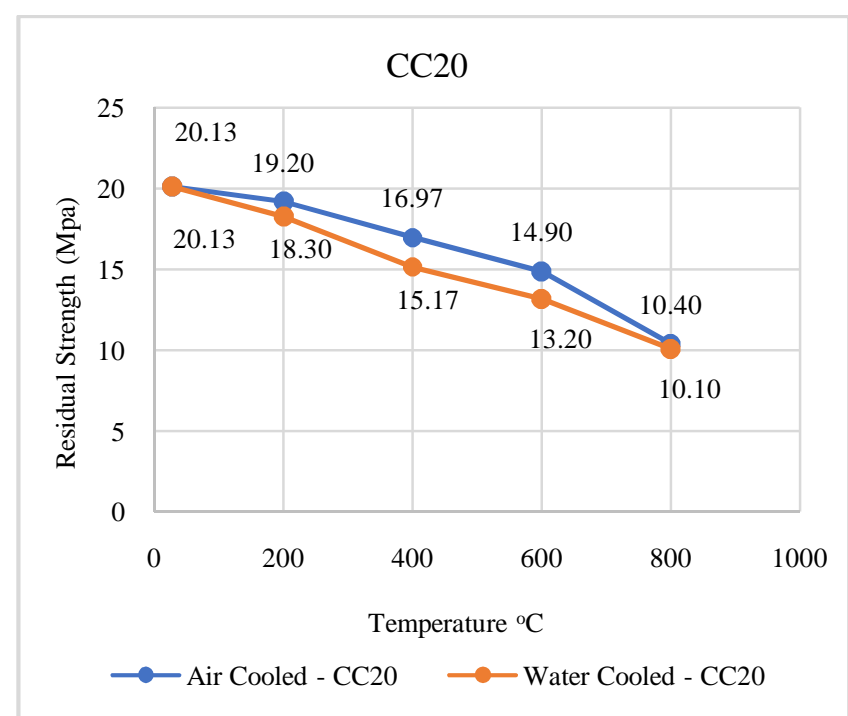

Figure 7:Influence of the method of cooling on RCS - CC20

When the specimens were allowed for air cooling, the specimens were initially subjected to elevated temperatures and then was allowed to return to room temperature gradually over 24 hours. So, the heat transfer mechanism would be comparatively slower smoother. But in case of water cooling, specimens once after attaining the peak temperatures were subjected to quick cooling by spraying water. The sudden reduction in temperature causes thermal shock in specimens. Water is present in the concrete matrix in the form of physically and chemically bound water. Loss of this water through evaporation induces extensive inner cracking. Also, a sudden decrease in temperature happens when specimens are subjected to water cooling. This creates a thermal gradient which in turn causes stress concentrations at different locations inside the specimen [14]. This resulted in the decreases the performance of water-cooling method when compared to air cooling method. 


\subsection{UPV of specimens}

The UPV of specimens with CPAexposed to elevated temperature and subjected to air cooling regime are shown in figure 8. The UPV of CC05 specimens were more than that of $\mathrm{CM}$ at all exposure conditions. At $200{ }^{\circ} \mathrm{C}, \mathrm{CM}, \mathrm{CC} 05$, $\mathrm{CC} 10$ and $\mathrm{CC} 15$ possessed excellent quality. At $400{ }^{\circ} \mathrm{C}$, all mixes showed good quality. At $600{ }^{\circ} \mathrm{C}, \mathrm{CM}$ and $\mathrm{CC} 05$ showed good quality and the rest of the mixes had medium quality. The quality of specimens after being exposed to 800 ${ }^{\circ} \mathrm{C}$ reduced drastically and all the specimens showed doubtful quality.

The results of UPV tests carried out on specimens blended with CPA exposed to elevated temperature and subjected to water cooling are shown in figure 9. The UPV values were found to be less than that of the corresponding values obtained for specimens with CPA, subjected to air cooling. After exposing to $200{ }^{\circ} \mathrm{C}$, the $\mathrm{CM}, \mathrm{CC} 05$ and $\mathrm{CC} 10$ showed excellent quality. Similarly, at $400{ }^{\circ} \mathrm{C}$, all the mixesshowed good quality and the UPV values were in the range of $3691 \mathrm{~m} / \mathrm{s}$ to $4117 \mathrm{~m} / \mathrm{s}$. At $600{ }^{\circ} \mathrm{C}$, the UPV values ranged between $2868 \mathrm{~m} / \mathrm{s}-3312 \mathrm{~m} / \mathrm{s}$. CM, CC05, CC10 and CC15showed medium quality and CC20 showed doubtful quality. At $800{ }^{\circ} \mathrm{C}$, all the specimens were of doubtful quality.

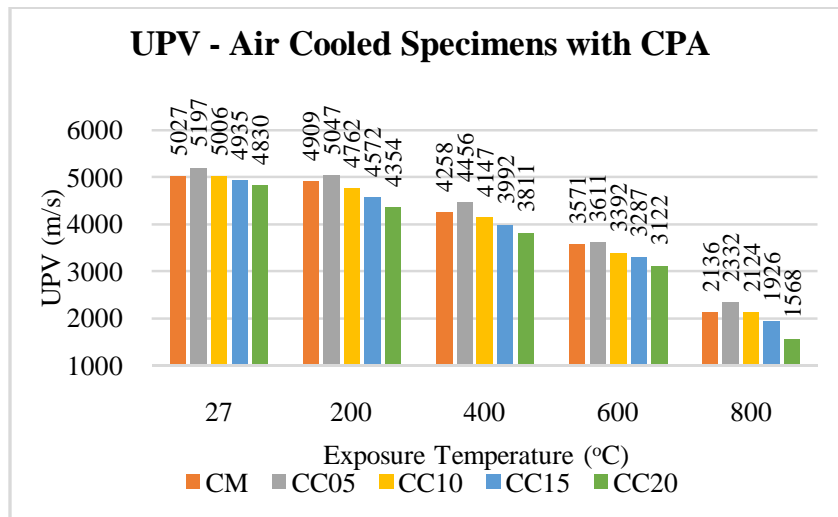

Figure 8: UPV of Specimens exposed to elevated temperatures and subjected to air cooling regime

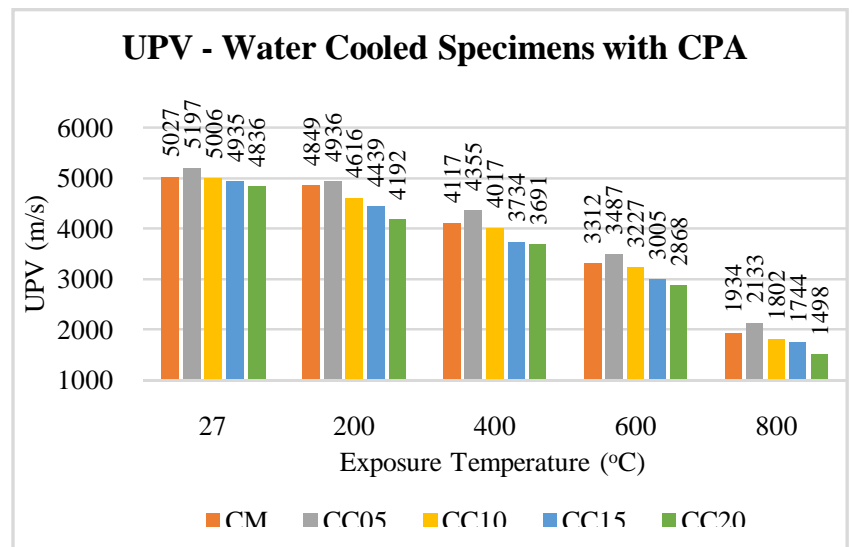

Figure 9: UPV of Specimens exposed to elevated temperatures and subjected to water cooling regime
Intense alterations happen to the microstructural characteristics of concrete when the specimens are subjected to elevated temperatures and this attributes to the variations observed in the UPV. The number of air voids within concrete increases above $450{ }^{\circ} \mathrm{C}$ due to disintegration of CSH gel and it will, in turn, result in the lower values of UPV [15]. Several other additives also have improved these types of desirable concrete characteristics. [16,17]

\subsection{Physical Appearance of Specimens After Exposing to Elevated Temperatures.}

Observing the specimens exposed to elevated temperature with naked eye provides an approximate idea on the overall physical condition of the specimens. Every Air-cooled and water-cooled specimen were observed and various physical features like surface texture and presence of cracks were checked.Damages happened mainly at $600{ }^{\circ} \mathrm{C}$ and $800{ }^{\circ} \mathrm{C}$. Several cracks were formed on the specimen surface at 800 ${ }^{\circ} \mathrm{C}$. The detailed surface characteristics are shown in table 3

Table 3:Surface Textureof concrete at various temperatures

\begin{tabular}{|c|c|c|}
\hline $\begin{array}{c}\text { Exposure } \\
\text { Temperature }\end{array}$ & Mix & Surface Texture \\
\hline \multirow{5}{*}{$27^{\circ} \mathrm{C}$} & $\mathrm{CM}$ & Even \\
\hline & $\mathrm{CC} 05$ & Even \\
\hline & CC10 & Even \\
\hline & CC15 & Even \\
\hline & CC20 & Even \\
\hline \multirow{5}{*}{$200^{\circ} \mathrm{C}$} & $\mathrm{CM}$ & Even \\
\hline & $\mathrm{CC} 05$ & Even \\
\hline & $\mathrm{CC} 10$ & Even \\
\hline & CC15 & Even \\
\hline & CC20 & Even \\
\hline \multirow{5}{*}{$400^{\circ} \mathrm{C}$} & $\mathrm{CM}$ & Even \\
\hline & $\mathrm{CC} 05$ & Even \\
\hline & CC10 & Even \\
\hline & CC15 & Even \\
\hline & CC20 & Even \\
\hline \multirow{5}{*}{$600^{\circ} \mathrm{C}$} & $\mathrm{CM}$ & Small cracks \& Rough \\
\hline & $\mathrm{CC} 05$ & Small cracks \& Rough \\
\hline & $\mathrm{CC} 10$ & Rough \\
\hline & CC15 & Rough \\
\hline & CC20 & Rough \\
\hline \multirow{5}{*}{$800^{\circ} \mathrm{C}$} & $\mathrm{CM}$ & $\begin{array}{c}\text { Cracks \& } \\
\text { Disintegration }\end{array}$ \\
\hline & $\mathrm{CC} 05$ & $\begin{array}{c}\text { Cracks \& } \\
\text { Disintegration }\end{array}$ \\
\hline & $\mathrm{CC} 10$ & $\begin{array}{c}\text { Cracks \& } \\
\text { Disintegration }\end{array}$ \\
\hline & CC15 & $\begin{array}{c}\text { Cracks \& } \\
\text { Disintegration }\end{array}$ \\
\hline & $\mathrm{CC} 20$ & $\begin{array}{c}\text { Cracks \& } \\
\text { Disintegration }\end{array}$ \\
\hline
\end{tabular}

\section{CONCLUSION}

This paper focused on the impact of elevated temperature environments on the performance of concrete containing a supplementary cementitious material derived from coir 
Industryi.e, CPA.From the results obtained, the following inferences were made.

- At all percentages of cement replacements, the compressive strength got reduced with increase in exposure temperature.

- At a particular temperature, the residual compressive strength of both air and water-cooled specimens increased with increase in CPA content.

- Under identical exposure temperature environments, air cooling method was found to be a better option than water cooling method.

- With an increase in temperature and CPA content, UPV got reduced

- It can be concluded that, on a strength point of view, when structures are exposed to elevated temperature conditions, adopting air cooling method will be a better option than water cooling method air cooling method will be more effective in recovering the desirable structural properties

\section{REFERENCES}

[1] US Geological Survey, Mineral Commodity Summaries $2018<$ https://minerals.usgs.gov/minerals/ pubs/mcs/2018/mcs2018.pdf> (05 January 2019), 2019.

[2] FAO 2014 - FAOSTAT - Food and Agriculture Organization of the United Nation.

[3] Brasileiro, Gisela Azevedo Menezes, Jhonatas Augusto Rocha Vieira, and Ledjane Silva Barreto. "Use of coir pith particles in composites with Portland cement." Journal of environmental management 131 (2013): 228238.

[4] Ravindranath, Das Anita, and S. Radhakrishnan. "Coir Pith-Wealth from Waste-A Reference." Published on the Occasion of the India International Coir Fair (2016).

[5] Hertz, Kristian Dahl. "Concrete strength for fire safety design." Magazine of Concrete Research 57.8 (2005): 445-453.

[6] Arioz, Omer. "Effects of elevated temperatures on properties of concrete." Fire safety journal 42.8 (2007): 516-522.

[7] Zega, C. J., and A. A. Di Maio. "Recycled concrete exposed to high temperatures." Magazine of Concrete Research 58.10 (2006): 675-682. https://doi.org/10.1680/macr.2006.58.10.675

[8] Lin, Y., Hsiao, C., Yang, H., \& Lin, Y. F. (2011). The effect of post-fire-curing on strength-velocity relationship for nondestructive assessment of firedamaged concrete strength. Fire Safety Journal, 46(4), 178-185

[9] Guo, Y. C., Zhang, J. H., Chen, G. M., \&Xie, Z. H. (2014). Compressive behaviour of concrete structures incorporating recycled concrete aggregates, rubber crumb and reinforced with steel fibre, subjected to elevated temperatures. Journal of cleaner production, $72,193-203$

[10] IS 12269:2013. 53 Grade Ordinary Portland Cement by Bureau of Indian Standards

[11] Bureau of Indian Standards. 2009. Guidelines for Concrete Mix Design Proportioning, IS 10262:2009, New Delhi

[12] Bureau of Indian Standards, Method of Tests for Strength of Concrete, IS 516: 1959, New Delhi, 1959

[13] Non-destructive Testing of Concrete - Methods of Test, Part 1: Ultrasonic Pulse Velocity, IS13311 (Part 1):1992, Bureau of Indian Standards, New Delhi. 199928

[14] Tanaçan, L., Ersoy, H. Y., \&Arpacioğlu, Ü. (2009). Effect of high temperature and cooling conditions on aerated concrete properties. Construction and Building Materials, 23(3), 1240-1248.

[15] Topcu, A. Demir 19. I.B. 2002. Effect of fire and elevated temperature on reinforced concrete structures, Bull. Chamber of Civ. Eng. Eskisehir Branch, pages 34-36

[16] Kumar, K. H., Shabarish, K. C. V., Bhanu, G., Prasad, K. D. V., \& Kumar, C. S. (2020). An Experimental Study on Effect of Replacing Natural Sand by Quarry Dust and Saw Dust on Properties of Concrete. International Journal, 8(5). https://doi.org/10.30534/ijeter/2020/71852020

[17] Ramakrishna, B., Harshini, B., Lakshmi, G. I., \&Sangireddy, K. (2020). Influence of fly ash on the properties of recycled coarse aggregate concrete. International Journal, 8(5). 